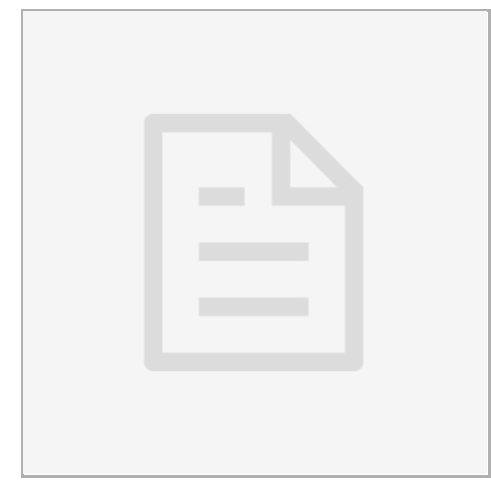

JUL 13, 2021

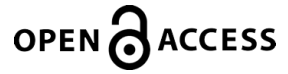

DOI:

dx.doi.org/10.17504/protocol s.io.bu2bnyan

Protocol Citation: Jorge Machado Alba 2021. Pharmacological management and potentially inappropriate prescriptions for patients with acne. protocols.io https://dx.doi.org/10.17504/p rotocols.io. bu2bnyan

License: This is an open access protocol distributed under the terms of the Creative Commons Attribution License, which permits unrestricted use, distribution, and reproduction in any medium, provided the original author and source are credited

Protocol status: Working We use this protocol and it's working

Created: May 14, 2021

Last Modified: Jul 13, 2021

PROTOCOL integer ID: 49955

\section{(3) Pharmacological management and potentially inappropriate prescriptions for patients with acne}

Jorge Machado Alba ${ }^{1}$

${ }^{1}$ Universidad Tecnológica de Pereira

Jorge Machado Alba

\title{
ABSTRACT
}

Introduction. Acne is a chronic inflammatory disease that involves the pilosebaceous follicle and mainly affects adolescents and young adults. Its pharmacological treatment involves topical and systemic medications, but a heterogeneous group of drugs may exacerbate or induce skin lesions. The aim was to identify the pharmacological management and medications related to the exacerbation of skin lesions in patients diagnosed with acne.

Methods. This was a cross-sectional study that identified the outpatient medication prescription patterns of patients with acne from a dispensing database of 8.5 million members of the Colombian Health System. Sociodemographic and pharmacological variables and the identification of prescriptions that were potentially inappropriate due to the risk of worsening acne were considered.

Results. A total of 21,604 patients with acne were identified. Their median age was 20.8 years [interquartile range: $17.3-27.3$ years], and $60.7 \%$ were women. Treatment mainly involved antibiotics (79.9\% of patients), especially doxycycline $(66.0 \%)$ and retinoids $(55.7 \%)$. A total of $17.2 \%$ of the patients had potentially inappropriate prescriptions, predominantly the use of progestogens with androgenic properties (8.9\%). Women (OR:3.55; 95\%Cl:3.24-3.90) and patients with pathologies such as systemic lupus erythematosus (OR:18.61; 95\%Cl:7.23-47.93) and rheumatoid arthritis (OR:10.80; 95\% Cl:5.02-23.23) were more likely to receive inappropriate prescriptions, and the risk increased with each year of life gained (OR:1.02; 95\%Cl:1.02-1.03).

Conclusion. Patients with acne are excessively treated with systemic antibiotics, counter to clinical practice guidelines. Approximately one-fifth of these patients received some potentially inappropriate medication that could exacerbate their skin lesions.

\section{ATTACHMENTS}

BD_acne_PPI.xlsx 
Keywords: Acne Vulgaris;

Anti-Bacterial Agents;

Retinoids; Inappropriate

Prescribing;

Pharmacoepidemiology. 